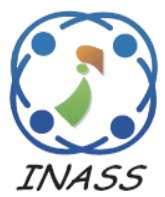

\title{
Destinations Ratings Based Multi-Criteria Recommender System for Indonesian Halal Tourism Game
}

\author{
Yunifa Miftachul Arif ${ }^{1,2 *}$ \\ Hani Nurhayati $^{1}$
Mochamad Hariadi $^{2,3}$ \\ ${ }^{1}$ Department of Informatics Engineering, Universitas Islam Negeri Maulana Malik Ibrahim, Malang, Indonesia \\ ${ }^{2}$ Department of Electrical Engineering, Institut Teknologi Sepuluh Nopember, Surabaya, Indonesia \\ ${ }^{3}$ Department of Computer Engineering, Institut Teknologi Sepuluh Nopember, Surabaya, Indonesia \\ * Corresponding author's Email: yunif4@ti.uin-malang.ac.id
}

\begin{abstract}
Halal tourism is one of the tourism products that have the prospect of contributing to economic growth in Indonesia. Therefore, the government needs to increase promotions to increase tourist interest in halal tourism destinations in Indonesia. Game is one of the alternative promotional media that can also function as an educational medium for choosing halal tourism that is fun for potential tourists. This study proposes a recommendation system to support knowledge sources in the Indonesian halal tourism game. We use destinations ratings-based multi-criteria recommender system (MCRS) to generate recommendation rankings as a reference for visualizing halal travel for players as potential tourists. This method improves the ability of the conventional tourism recommendation system, which is generally based on a single criterion. In this study, we use eight destinations rating criteria as a reference for calculating the recommender system in the halal tourism game. Each of these criteria is a reference for tourists' assessment of halal tourist destinations in Indonesia. Next, we integrate the cosine-based similarity technique in MCRS to measure the level of similarity between players and previous tourist data sets. This research's testing phase uses the theme of halal tourism destinations in the Batu City area. The test results show that the number and composition of the tourism destinations item rating as input of the recommender system affect the accuracy, precision, recall, and F1 scores. Based on 40 experiments with different tourism destination item rating input configurations, it shows that the average value of accuracy $=0.60$, precision $=0.67$, recall $=0.64$ and $\mathrm{F} 1$ score $=0.65$.
\end{abstract}

Keywords: Halal tourism, Game, Multi-criteria recommender system, Destinations ratings.

\section{Introduction}

Tourism is one of the priority sectors of national development in Indonesia in addition to energy, maritime, industrial, and food areas. Currently, tourism is also experiencing growth and making a positive contribution to the national economy. However, this growth was insufficient to meet the contribution target to the national economy [1]. The Indonesian government, since 2016, has declared 10 tourism destinations that are development priorities [2]. The government needs to take advantage of all the opportunities and the diversity of characteristics that Indonesia has to achieve the tourist acceptance target that has been proclaimed. Indonesia's status as a country with the largest Muslim population globally is a distinct advantage that must be utilized in the development of tourism promotion. One form of development is targeting halal tourism products. This tourist travel concept is run based on Islamic law [3], where all the facilities, entertainment, clothing, food, to lodging are adjusted to the guidance of the Qur'an and Hadith [4].

Increasing the promotion of halal tourism is expected to increase the interest of local and international Muslim tourists. On the other hand, essential things must be optimized to increase promotion in the tourism sector, especially halal tourism, guaranteeing the availability of data and information for potential tourists. With the ease of getting information and recommendations, tourists 
can easily plan their travels [5]. The aftereffect is that it can trigger them to return and promote the destinations they have visited to other potential tourists.

Information and recommendations are essential knowledge for potential tourists before and during trip phases [6]. To get these two things, tourists usually rent a tour guide or explore independently through social media and the web using their mobile equipment, such as smartphones, ipads, and others [7]. However, this process adds to tourists' cost, time, and busyness in preparing for their travels. So that alternative media are needed that can be used as promotions and education for tourists, especially in choosing halal tourist destinations. In this study, we propose implementing serious games as promotional media and fun education for tourists. Where today, the game is one of the new media in digital marketing technology [8]. The use of games in tourism can help potential tourists improve their knowledge and travel experience $[9,10,11]$. In addition, the use of games as promotional media also brings significant benefits to developers, including increasing awareness of player needs, knowledge, and interest in brand content. [12, 13].

A game needs to get additional support from the recommendation system to provide the benefits of knowledge to its players [14]. With the development of a recommendation system, tourists can choose, compare and make decisions quickly [15]. In this study's case of tourism games, the main problem is how to produce recommendations for selecting halal tourist destinations for potential tourists. The reason is that selecting tourist destinations is essential knowledge for prospective tourists in preparing for their travels [16]. On the other hand, several things influence tourists in choosing tourist destinations, one of which is the destinations attribute factor [17]. These factors are attributes or characteristics attached to a tourist destination, for example, the facilities and services available [18]. Therefore, this study proposes a recommendation system for tourism games that can produce recommendations based on the similarity of rating the facilities and services available in tourist destinations by previous tourists. The assessment rating of these facilities and services must follow the reference criteria for halal tourism.

On the other hand, several approaches to recommender systems include content-based, collaborative filtering, knowledge-based, and hybrid. $[19,20]$. Several studies on tourist destination recommendation systems use different methods, such as opinion-mining technology [21] and Bayesian network with analytic hierarchy process [22]. The conventional method generally used in the recommendation system is to use a single criterion as a reference to produce recommendations. Using single criteria in the recommendation system means calculating recommendations based on one assessment criteria for only items [16]. The concept is not relevant if implemented in case studies that have more influence factors for selecting items, such as halal tourism. Where, more criteria can be used in evaluating halal tourism, including the availability of halal food or drinks, prayer rooms and ablution places, Qibla directions, Islamic entertainment, and others. [23]. With various criteria as a reference for evaluating halal tourism, we propose using a multicriteria approach to generate recommendations in the halal tourism game based on destinations ratings of Indonesian halal tourism. The method called the Multi-Criteria Recommender System (MCRS) has the characteristics of the recommendation results that are more precise than the single criteria approach [24].

This study built game environments, characters, objects, and user interfaces using the Unity game engine. Then we integrated Destinations Ratings (DR) based MCRS into the game design using C\# programming on the game engine. This research hopes to produce alternative media for promoting tourist destinations through tourism games with a recommendation system to help tourists learn about the selection of halal tourist destinations for them.

\subsection{Relate work}

Several studies have discussed how to incorporate tourism content into games. Xu et al., in a study, explained that tourism games contribute to more rewarding interactions with higher levels of satisfaction and increase awareness and loyalty to tourist destinations. The research in 2017 used the concept of a tourist travel scenario through visualization of treasure hunts in tourist destinations which aims to help visitors explore various areas and collect points, photos, memories, and experiences [9]. In another study, Correa et al. stated that tourism games require appropriate scenarios to focus on tourism content to develop well [25]. Furthermore, Swaca et al., in a study, explained that making tourism games can improve the process of tourist visits. Twelve techniques were described in the 2017 study, namely four each during the before, during, and post-visit phases. Techniques in the pre-visit phase include; the challenge of visit, the challenge of place and time, the challenge of public transit, and the challenge of the exhibit. Techniques during the phase of the visit include; story, completion, puzzles, and collectors. In comparison, the techniques in the postvisit phase include; quests, achievements, streaks, 
and progress [26]. Each of these techniques becomes a valuable reference in selecting and determining tourism game content in this research. One of the gaps in some research on game tourism is the need for in-game system support to increase knowledge transfer to players through a recommender system.

A recommender system is currently an important tool that supports game system performance, primarily to provide players with knowledge about selecting items in-game content. In a study, Looi et al. propose implementing a recommender system to provide knowledge to players about selecting and purchasing items in the Dota 2 game. The study uses the concept of a rule-based system that utilizes clustering for the developed logistic regression-based system. [14]. Further research conducted by González et al. explicitly discusses using the recommender system in serious games to rehabilitate patient health. Their research aims to produce a serious game that can motivate and increase player compliance to their treatment. The recommender system utilizes an intelligent system to analyze patient interactions and history to select the proper ingame training. The result is that the system can provide recommendations according to different players' difficulty levels and abilities [27]. Even though they have different content subjects, some of these studies are references for this research, especially to integrate recommender systems to select tourism destinations into the game.

Borràs et al. stated that generally, tourism recommender systems have a web-based or mobilebased interface. With the development of mobile technology today, mobile-based recommendation systems are more in demand than web-based ones. The reason is that the mobile-based recommendation application allows users to interact more efficiently, even with a smaller display. The research in 2014 discussed several functions of the recommendation system in the tourism sector. Among them are destination selection, tourism attraction ranking, and travel route planning [28]. Recommender systems based on web and mobile certainly have different user segments with all their advantages and disadvantages. But what needs to be highlighted is how users can use it with pleasure so that knowledge about tourist destinations is easier to understand. Therefore, in this study, we propose using games as a media base for a tourism recommender system that contains fun and challenges for its users.

In one study, Bahramian et al. explain several recommendations system approaches, including Content-Based, Collaborative Filtering, KnowledgeBased and Hybrid. Each of these approaches has different characteristics. In the Content-Based approach, the system generates recommendations based on the user's equal rating of all items. This method usually performs well when the user has a lot of historical records for learning. Collaborative Filtering generates recommendations based on the user's sense of preference. Knowledge-Based applies a reasoning mechanism to generate recommendations according to user preferences related to item characteristics. In comparison, the Hybrid approach combines several other approach models in the recommendation system [29]. Kzaz et al. state that two approaches commonly used in tourism recommender systems include the classical approach, including Content-Based and Collaborative Filtering, and non-classical approaches, including personalized approach and context-aware approach. [30]. The recommender system requires a better calculation concept than the classical or traditional approach, which generally uses single criteria to improve the accuracy and suitability of the recommendation results. Therefore, in this study, we propose using a multi-criteria-based recommender system to produce recommendations for destination selection in halal tourism games in Indonesia. This method has a high prospect of suitability in the context of a recommender system for selecting halal tourist destinations. The reason is that many factors can serve as reference criteria that influence potential tourists in choosing tourism destinations according to their travel plans [31].

Furthermore, Moussa et al. propose a personalized-based system that provides travelers with knowledge about choosing travel itineraries. The author develops a web-based system using the ELECTRE method to produce the most suitable itinerary for travelers [32]. In another study, Tenemaza et al. introduced a mobile applicationbased tourism destinations recommender system. They build a system by considering the tourist trip design problems to produce recommendations following changes in the tourism destination environment and tourist interest [33]. Santosa et al., in a study proposed a multi-criteria-based recommender system for the selection of tourist destinations using the Weighted Sum Model (WSM) method. The authors explain that the recommendations are generated based on the weighting of each criterion that they have previously defined [34]. However, every tourist certainly has different thoughts in giving weight or rating to each tourist destination where many factors influence tourists in choosing a tourist destination [17]. Therefore, in this study, we offer the concept of calculating the MCRS based on the similarity of rating criteria for each tourist destination item to the 


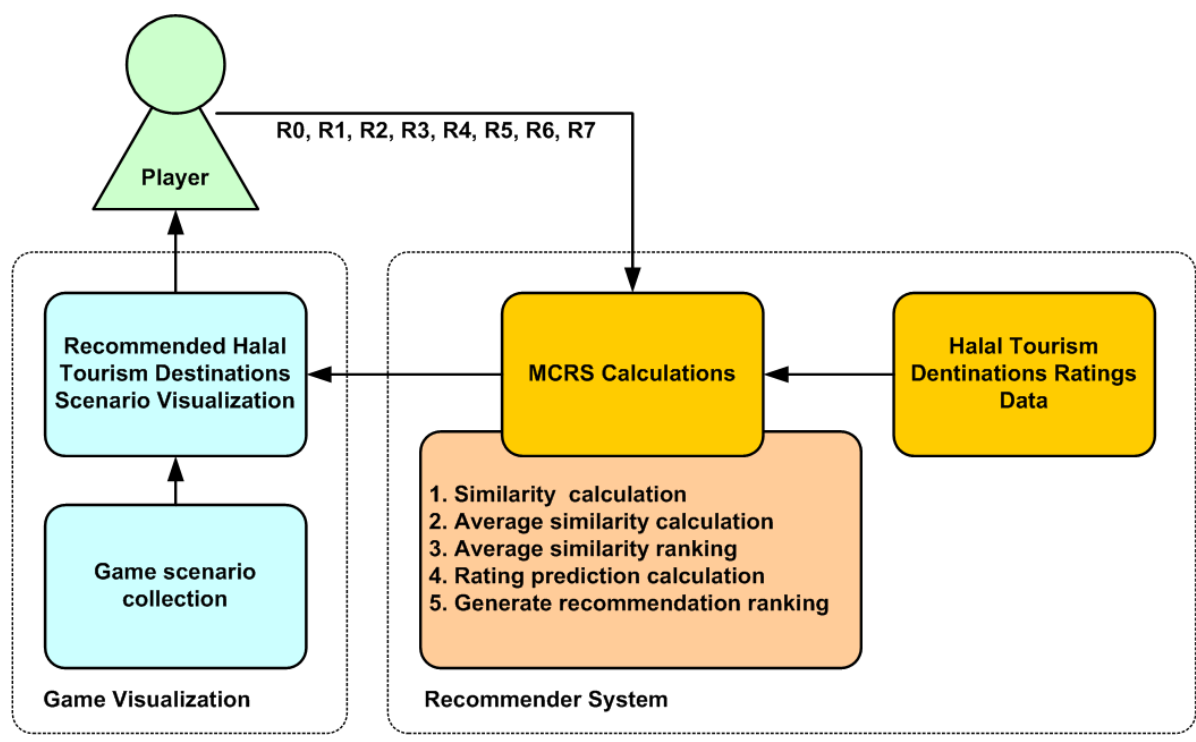

Figure. 1 Proposed system with MCRS for halal tourism game

rating data set from previous tourists. We determine each criterion based on the characteristics and attributes of halal tourist destinations discussed in several related papers.

\subsection{Contributions and organization of paper}

There is still little research that discusses recommender systems in games, especially those choosing halal tourist destinations. Therefore, we are motivated to produce a recommender system design for selecting halal tourist destinations in the game using MCRS based on tourist destinations rating ratings. This research also has several contributions, which we describe as follows. First, we offer a multicriteria recommender system to handle the selection of halal tourist destinations in the game as a scenario choice for players. The goal is for players to visualize the selection of halal travel suitable for them based on the similarity of the rating criteria for the assessment of tourist destinations with a collection of rating data from previous tourists. Second, in this study, we define 8 criteria that serve as a reference for rating each halal tourist destination. Third, the game system offers the concept of knowledge transfer regarding the choice of halal tourist destinations through visualization of travel scenarios for each recommendation.

Furthermore, to explain each step of the research, we divide this paper into several parts. After the introduction, the next section is the design and method, which explains the design and methods offered in this research. The next section is the result and discussion, which explains the test results and a description of the analysis that we carried out. Finally, we summarize the contents of this paper in the conclusion section.

\section{Design and method}

This study proposes using MCRS to generate recommendations for selecting tourist destinations visualized through scenario choices in halal tourism games. Therefore, the proposed system in this study has two main parts: the recommender system section and the game visualizations section. Fig. 1 shows the two main sections, which we explain and divide into supporting sections. The recommender system section has an MCRS calculation section based on halal tourism destinations rating data and ratings from layers. At the same time, the visualization game has a supporting part consisting of game scenario collection and recommended halal tourism destinations scenario visualization.

\subsection{Defining criteria}

Nicolau et al., in their research, explains that two main factors influence tourists in choosing tourism destinations in general, namely personal characteristics and destinations attributes [17]. Personal characteristics are the innate characteristics of tourists, such as gender, education, gender, hobbies, marital status, and area of origin. While the destinations attribute is an attribute attached to a tourist destination, for example, about the facilities, services available. This study uses the destinations attribute as a reference in generating recommendations using the MCRS method. In the context of choosing halal tourism, we define the destination's attribute according to several characteristics of halal tourism that have been defined in several previous studies, including [3] and [23]. This study uses the destinations attribute of halal 
Table 1. Halal tourism rating criteria

\begin{tabular}{|c|c|l|c|}
\hline Number & $\begin{array}{c}\text { Rating } \\
\text { Criteria }\end{array}$ & \multicolumn{1}{|c|}{ Criteria Description } & $\begin{array}{c}\text { Rating } \\
\text { Value }\end{array}$ \\
\hline 1. & $R_{1}$ & Availability of lodging or hotels with halal facilities and service & $1-10$ \\
\hline 2. & $R_{2}$ & Availability of halal restaurants or food outlets & $1-10$ \\
\hline 3. & $R_{3}$ & Separation of places of worship between male and female & $1-10$ \\
\hline 4. & $R_{4}$ & Separate male and female toilets & $1-10$ \\
\hline 5. & $R_{5}$ & Availability of clean and holy water & $1-10$ \\
\hline 6. & $R_{6}$ & Availability of halal shopping places & $1-10$ \\
\hline 7. & $R_{7}$ & $\begin{array}{l}\text { Availability of supporting information on tourist attractions such } \\
\text { as maps or directions to the mosque, information on halal outlets, } \\
\text { and qibla direction }\end{array}$ & $1-10$ \\
\hline 8. & $R_{0}$ & Overall Rating & $1-10$ \\
\hline
\end{tabular}

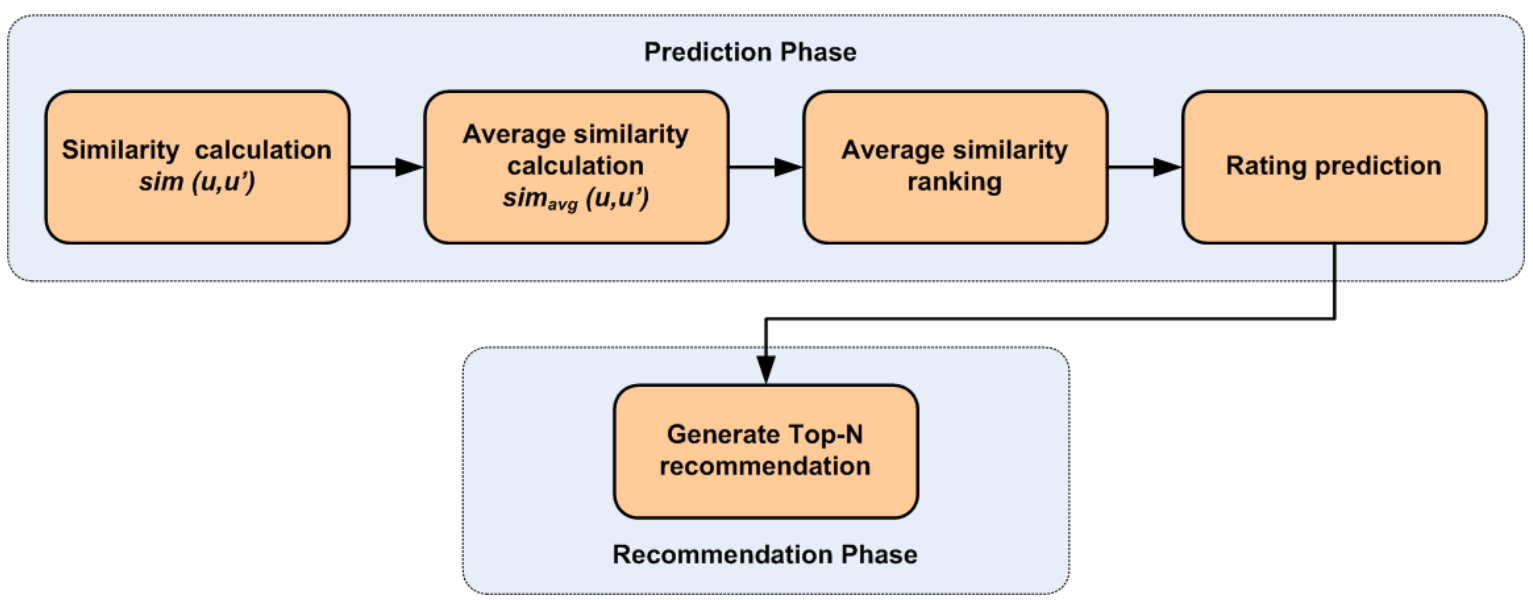

Figure. 2 MCRS phases in halal tourism game

tourism as a reference criterion in producing recommendations, as in Table 1. Each criterion becomes a reference for assigning value ratings to halal tourist destinations by tourists collecting rating data. In addition, the MCRS in this study also requires the input of rating criteria data from players as potential tourists to predict the similarity with previous tourist data.

\subsection{Multi-criteria recommender system for choosing tourism destinations}

The Multi-Criteria Recommender System (MCRS) generates recommendations that work by extending the traditional approach. This method expands through increasing the number of ranks to cover various item attributes and combining their ranks to improve prediction accuracy [24, 35]. MCRS also works based on criteria, a collection of various attributes that describe an item's quality. This method can choose to create a user utility model for specific items with an overall rating $R_{0}$ as well as user ratings of $R_{l}$ to $R_{n}$ for each individual criterion c (c $=1, \ldots$, $n$ ). But actually the system can also choose not to use an overall rating and only focus on assessing individual criteria. Eq. (1) shows the formula in the
MCRS method, where $R$ is the rating rating from the user $u$ against all criteria belonging to the item $i$. In this study, we position game players as users and halal tourism destinations as an item choice.

$$
R: u \times i \rightarrow R_{0} \times R_{1} \times \ldots \times R_{n}
$$

To carry out its function, MCRS works in two phases, namely prediction, and recommendation. Prediction is the phase where the system calculates predictions from user preferences, while the recommendation is the phase where users get item recommendations [19]. Fig. 2 shows the sequence of processes for generating recommendations for selecting halal tourism destinations using the MCRS method, divided into these two phases.

In this study, we define a player as a user who wants to get recommendations for halal tourist attractions through games. To produce these recommendations, we use the MCRS method based on a heuristic approach. The approach, also known as neighborhood-based collaborative filtering, has several steps to determine user $u$. The first step is to calculate the similarity rating on each user criterion $u$ to the previous tourist data as $u$ '. To find rating similarities $\operatorname{sim}\left(u, u^{\prime}\right)$ we use a cosine-based 
Table 2. The recommendation results based on the number of tourist destination rating items

\begin{tabular}{|c|c|c|c|c|c|c|c|c|}
\hline \multirow[b]{2}{*}{ Trials } & \multirow[b]{2}{*}{ Number of Items } & \multirow[b]{2}{*}{ Result } & \multicolumn{6}{|c|}{ Top N Recommendation } \\
\hline & & & $\mathbf{N}=\mathbf{1}$ & $\mathbf{N}=\mathbf{2}$ & $\mathbf{N}=\mathbf{3}$ & $N=4$ & $\mathbf{N}=\mathbf{5}$ & $\begin{array}{c}\text { Avera } \\
\text { ge }\end{array}$ \\
\hline \multirow{4}{*}{1} & \multirow{4}{*}{$\begin{array}{c}2 \\
\text { (Jatim Park } 1, \text { Jatim Park }\end{array}$} & Accuracy & 0.77 & 0.60 & 0.51 & 0.49 & 0.47 & 0.57 \\
\hline & & Precision & $\mathbf{0 . 8 0}$ & 0.60 & 0.57 & 0.57 & 0.58 & 0.62 \\
\hline & & Recall & 0.73 & 0.67 & 0.59 & 0.59 & 0.58 & 0.63 \\
\hline & & F1 Score & 0.76 & 0.63 & 0.58 & 0.58 & 0.58 & 0.63 \\
\hline \multirow{4}{*}{2} & \multirow{4}{*}{$\begin{array}{c}3 \\
\text { (Jatim Park 1, Jatim Park } \\
\text { 2, Jatim Park 3) }\end{array}$} & Accuracy & 0.79 & 0.71 & 0.59 & 0.48 & 0.42 & 0.60 \\
\hline & & Precision & 0.60 & 0.65 & 0.60 & 0.57 & 0.52 & 0.59 \\
\hline & & Recall & 1.00 & 0.87 & 0.72 & 0.57 & 0.52 & 0.74 \\
\hline & & F1 Score & 0.75 & 0.74 & 0.65 & 0.57 & 0.52 & 0.65 \\
\hline \multirow{4}{*}{3} & \multirow{4}{*}{$\begin{array}{c}4 \\
\text { (Jatim Park 1, Jatim Park } \\
\text { 2, Jatim Park 3, Museum } \\
\text { Angkut) }\end{array}$} & Accuracy & 0.75 & 0.56 & 0.44 & 0.34 & 0.34 & 0.49 \\
\hline & & Precision & 0.60 & 0.50 & 0.47 & 0.37 & 0.42 & 0.47 \\
\hline & & RecalI & 0.86 & 0.67 & 0.52 & 0.42 & 0.42 & 0.57 \\
\hline & & F1 Score & 0.70 & 0.57 & 0.49 & 0.39 & 0.42 & 0.52 \\
\hline \multirow{4}{*}{4} & \multirow{4}{*}{$\begin{array}{c}5 \\
\text { (Jatim Park 1, Jatim Park } \\
\text { 2, Jatim Park 3, Museum } \\
\text { Angkut, Selecta) }\end{array}$} & Accuracy & 0.68 & 0.57 & 0.55 & 0.50 & 0.47 & 0.55 \\
\hline & & Precision & 0.60 & 0.60 & 0.63 & 0.60 & 0.58 & 0.60 \\
\hline & & Recall & 0.67 & 0.60 & 0.61 & 0.58 & 0.58 & 0.61 \\
\hline & & F1 Score & 0.63 & 0.60 & 0.62 & 0.59 & 0.58 & 0.60 \\
\hline
\end{tabular}

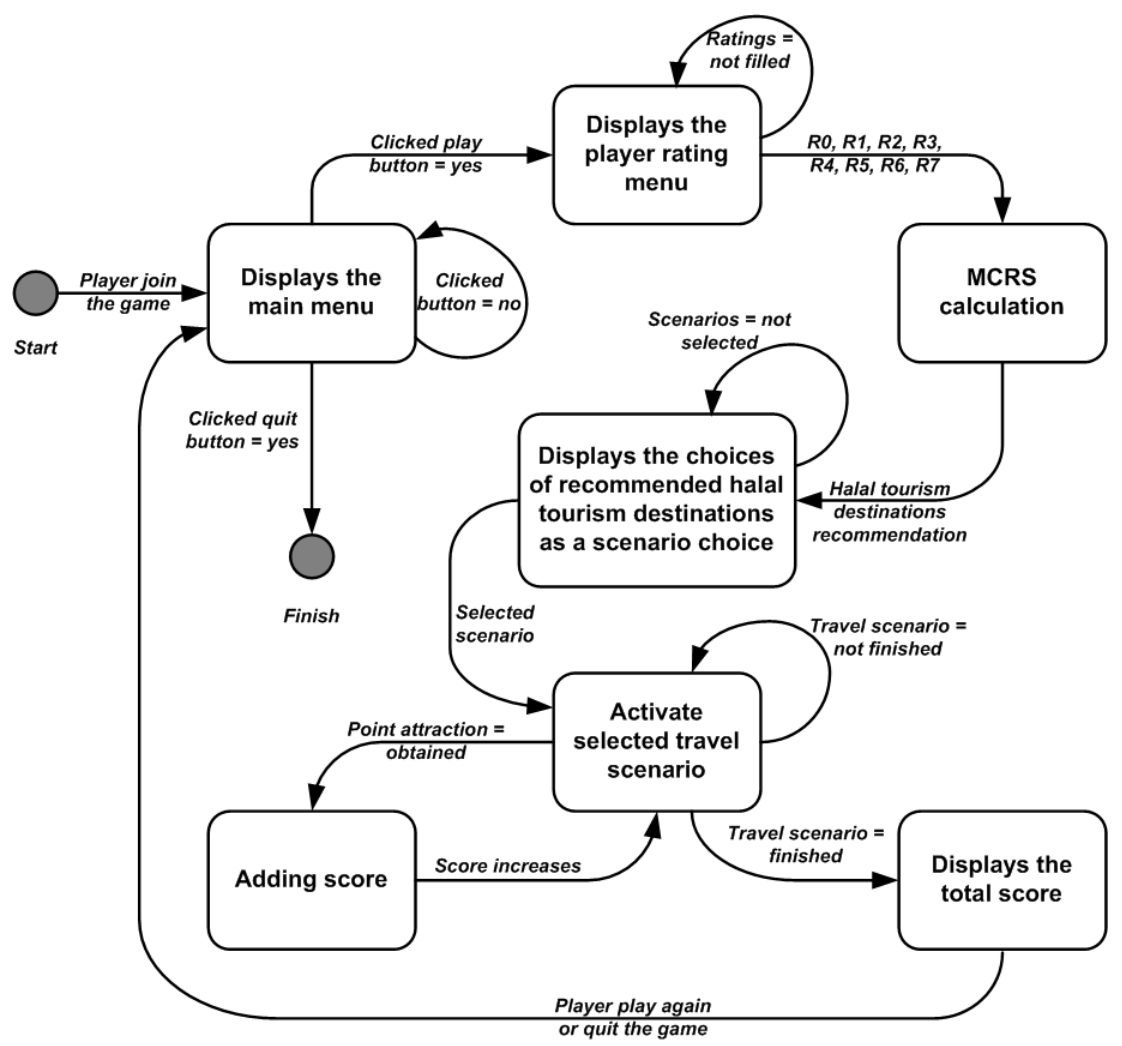

Figure. 3 Game scenario rules in FSM

similarity calculation with a formula like in Eq. (2). Where $I\left(u, u^{\prime}\right)$ is the item that gets the rating from the user $u$ and $u$, while $R(u, i)$ is the rating from the user $u$ for the item $i$.

$$
\operatorname{sim}\left(u, u^{\prime}\right)=\frac{\sum_{i \epsilon I\left(u, u^{\prime}\right)} R(u, i) R\left(u^{\prime}, i\right)}{\sqrt{\sum_{i \in I\left(u, u^{\prime}\right)} R(u, i)^{2}} \sqrt{\sum_{i \in I\left(u, u^{\prime}\right)} R(u, i)^{2}}}
$$

The next step in the heuristic-based approach is to calculate the individual similarity values of $n+1$. In this process, we calculate the average similaritysim $_{\text {avg }}\left(u, u^{\prime}\right)$ between user $u$ and previous tourist $u^{\prime}$ as in Eq. (3). While the notation $\operatorname{sim}_{c}\left(u, u^{\prime}\right)$ in the equation is a representation of the value of similarity criteria $c$ between user $u$ and previous tourist data $u^{\prime}$. The calculation results can show users with a higher level of similarity than other 
users using average similarity. The value of $n$ is the number of criteria that get a rating from the user.

$$
\operatorname{sim}_{\text {avg }}\left(u, u^{\prime}\right)=\frac{1}{n+1} \sum_{c=0}^{n} \operatorname{sim}_{c}\left(u, u^{\prime}\right)
$$

After the system gets the similarity value between user $u$ and each previous tourist as user $u$ ' using average similarity, the next step is to rank and find the highest similarity. The system assumes that user $u$ ' with the highest value is the most similar to user $u$. Then the fourth step is rating prediction, which is a process of taking the $R_{0}$ rating value for each tourism destination item from user $u$ ' which is the most similar, and filling it in for each $R_{0}$ value that is still empty for user $u$. The last step in the recommendation phase is to generate a Top-N recommendation. The system ranks all $R_{0}$ values for user $u$, resulting in a sequence of $R_{0}$ values for all tourism destinations items from the highest to the lowest. The sequence of $R_{0}$ values then becomes the input for the next sub-system, namely game visualization.

\subsection{Game visualization}

The visualization game is one part that has an essential role in transferring travel knowledge in halal tourist destinations following the recommendations from the recommender system. This section builds virtual environments and objects for each halal tourist destination item from the recommender system. The virtual environment and objects support the Indonesian Halal Tourism Game (IHTG) proposed in this study.

Fig. 3 shows the game scenario rules design in the form of a Finite State Machine (FSM) to explain the activities of the game system. First, when the game runs and the player joins, the system displays the main menu, the start of the in-game display. Next, the game system displays a rating menu to ask players to enter $R_{0}, R_{1}, R_{2}, R_{3}, R_{4}, R_{5}, R_{6}$, and $R_{7}$ from one of the halal tourism destinations they know. Each of these ratings becomes the input for MCRS calculations to produce a recommendation ranking, which the system then displays as a scenario choice for players. They can choose one of the scenarios where the system runs it as a form of knowledge transfer about travel complete with visualization of the environment and objects according to the selected halal tourist destination built similar to the original. When in the selected scenario, the game directs the player to do a virtual exploration to find a point of attraction. When you get the point attraction, the system will add it as a player score. After the player has finished exploring the selected scenario, the system displays the total score that the player has obtained during the exploration.

\section{Result and discussion}

This section explains system development and testing results in two sub-sections: recommender system results and game implementation results. To support this trial, we use 100 rating data for tourist destination assessments from tourists. We obtained this data by distributing an assessment questionnaire on 14 tourist destination items in Batu City, including Jatim Park 1, Jatim Park 2, Jatim Park 3, Museum Angkut, Selecta, Batu Night Spectacular (BNS), Eco Green Park, Alun-alun Batu, Kusuma Agro, Cangar, Coban Talun, Songgoriti Baths, Coban Rais, and Predator Fun Park. This study uses 90 data for reference for MCRS calculations and 10 data as test samples. Furthermore, to visualize the recommendations for choosing halal tourist destinations in Batu City, we use Unity as an engine in the game development process. We build user interfaces, objects, characters, virtual environments, and game scenarios through the game engine.

\subsection{Recommender system result}

This study's recommender system testing phase aims to analyze the accuracy and precision of the recommendations produced. This test uses the configuration matrix method to produce accuracy, precision, recall and F1 scores based on differences in the values of True Positive (TF), True Negative (TN), False Positive (FP), and False Negative (FN). $\mathrm{TN}$ is the number of recommended items produced by the system also recommended by test users, while TN is the number of items that are not recommended by the system and test users. Furthermore, FP is the number of items recommended by the system but not in the set recommended by the test user. At the same time, FN describes the number of items recommended by the test user but not included in the system recommendation ranking [36, 37]. The following equation is a formula for accuracy, precision, recall and F1 score [8].

$$
\begin{gathered}
\text { accuracy }=\frac{T P+T N}{T P+T N+F P+F N} \\
\text { precision }=\frac{T P}{T P+F P} \\
\text { recall }=\frac{T P}{T P+F N}
\end{gathered}
$$


Table 3. The recommendation results based on the difference composition of tourist destination rating items

\begin{tabular}{|c|c|c|c|c|c|c|c|c|}
\hline \multirow[b]{2}{*}{ Experiment } & \multirow[b]{2}{*}{ Items Combination } & \multirow[b]{2}{*}{ Result } & \multicolumn{6}{|c|}{ Top N Recommendation } \\
\hline & & & $\begin{array}{c}\mathbf{N}= \\
\mathbf{1}\end{array}$ & $\begin{array}{c}\mathbf{N}= \\
2\end{array}$ & $\begin{array}{c}\mathrm{N}= \\
\mathbf{3}\end{array}$ & $\begin{array}{c}\mathrm{N}= \\
4\end{array}$ & $\mathbf{N}=\mathbf{5}$ & Average \\
\hline \multirow{4}{*}{1} & \multirow{4}{*}{ Jatim Park 1, Jatim Park 2} & Accuracy & 0.77 & 0.60 & 0.51 & 0.49 & 0.47 & 0.57 \\
\hline & & Precision & 0.80 & 0.60 & 0.57 & 0.57 & 0.58 & 0.63 \\
\hline & & Recall & 0.73 & 0.67 & 0.59 & 0.59 & 0.58 & 0.63 \\
\hline & & F1 Score & 0.76 & 0.63 & 0.58 & 0.58 & 0.58 & 0.63 \\
\hline \multirow{4}{*}{2} & \multirow{4}{*}{ Jatim Park 2, Jatim Park 3} & Accuracy & $\mathbf{0 . 8 2}$ & 0.68 & 0.60 & 0.51 & 0.46 & 0.61 \\
\hline & & Precision & 0.90 & 0.70 & 0.67 & 0.60 & 0.56 & 0.69 \\
\hline & & Recall & 0.75 & 0.74 & 0.69 & 0.60 & 0.56 & 0.67 \\
\hline & & F1 Score & 0.82 & 0.72 & 0.68 & 0.60 & 0.56 & 0.68 \\
\hline \multirow{4}{*}{3} & \multirow{4}{*}{$\begin{array}{c}\text { Jatim Park 3, Museum } \\
\text { Angkut }\end{array}$} & Accuracy & 0.44 & 0.44 & 0.44 & 0.44 & 0.44 & 0.44 \\
\hline & & Precision & 0.70 & 0.75 & 0.67 & 0.60 & 0.54 & 0.65 \\
\hline & & Recall & 0.64 & 0.71 & 0.67 & 0.60 & 0.54 & 0.63 \\
\hline & & F1 Score & 0.67 & 0.73 & 0.67 & 0.60 & 0.54 & 0.64 \\
\hline \multirow{4}{*}{4} & \multirow{4}{*}{ Museum Angkut, Selecta } & Accuracy & 0.63 & 0.63 & 0.64 & $\mathbf{0 . 6 5}$ & 0.53 & 0.62 \\
\hline & & Precision & 0.80 & 0.75 & 0.73 & 0.77 & 0.64 & 0.74 \\
\hline & & Recall & 0.50 & 0.62 & 0.71 & $\mathbf{0 . 7 2}$ & 0.64 & 0.64 \\
\hline & & F1 Score & 0.61 & 0.68 & 0.72 & 0.75 & 0.64 & 0.68 \\
\hline \multirow{4}{*}{5} & \multirow{4}{*}{ Selecta, BNS } & Accuracy & 0.68 & 0.58 & 0.51 & 0.44 & 0.42 & 0.53 \\
\hline & & Precision & 0.80 & 0.65 & 0.57 & 0.52 & 0.52 & 0.61 \\
\hline & & Recall & 0.57 & 0.59 & 0.59 & 0.52 & 0.52 & 0.56 \\
\hline & & F1 Score & 0.67 & 0.62 & 0.58 & 0.52 & 0.52 & 0.58 \\
\hline \multirow{4}{*}{6} & \multirow{4}{*}{ BNS, Eco Green Park } & Accuracy & 0.77 & 0.70 & 0.71 & 0.64 & 0.59 & 0.68 \\
\hline & & Precision & 0.80 & 0.74 & $\mathbf{0 . 7 7}$ & 0.75 & 0.70 & $\mathbf{0 . 7 5}$ \\
\hline & & Recall & 0.72 & 0.75 & 0.79 & 0.71 & 0.70 & 0.73 \\
\hline & & F1 Score & 0.76 & 0.75 & $\mathbf{0 . 7 8}$ & 0.73 & 0.70 & 0.74 \\
\hline \multirow{4}{*}{7} & \multirow{4}{*}{$\begin{array}{c}\text { Eco Green Park, Alun-alun } \\
\text { Batu }\end{array}$} & Accuracy & 0.69 & 0.57 & 0.55 & 0.48 & 0.49 & 0.56 \\
\hline & & Precision & 0.70 & 0.60 & 0.60 & 0.55 & 0.60 & 0.61 \\
\hline & & Recall & 0.64 & 0.60 & 0.64 & 0.59 & 0.60 & 0.61 \\
\hline & & F1 Score & 0.67 & 0.60 & 0.62 & 0.57 & 0.60 & 0.61 \\
\hline \multirow{4}{*}{8} & \multirow{4}{*}{$\begin{array}{c}\text { Alun-alun Batu, Kusuma } \\
\text { Agro }\end{array}$} & Accuracy & 0.69 & 0.64 & 0.59 & 0.55 & 0.55 & 0.60 \\
\hline & & Precision & 0.70 & 0.70 & 0.67 & 0.65 & 0.66 & 0.68 \\
\hline & & Recall & 0.64 & 0.67 & 0.67 & 0.63 & 0.66 & 0.65 \\
\hline & & F1 Score & 0.67 & 0.68 & 0.67 & 0.64 & 0.66 & 0.66 \\
\hline \multirow{4}{*}{9} & \multirow{4}{*}{ Kusuma Agro, Cangar } & Accuracy & 0.54 & 0.46 & 0.42 & 0.42 & 0.39 & 0.45 \\
\hline & & Precision & 0.50 & 0.50 & 0.47 & 0.52 & 0.48 & 0.49 \\
\hline & & Recall & 0.42 & 0.45 & 0.47 & 0.49 & 0.48 & 0.46 \\
\hline & & F1 Score & 0.45 & 0.48 & 0.47 & 0.51 & 0.48 & 0.48 \\
\hline \multirow{4}{*}{10} & \multirow{4}{*}{ Cangar, Coban Talun } & Accuracy & 0.61 & 0.59 & 0.53 & 0.50 & 0.44 & 0.53 \\
\hline & & Precision & 0.70 & 0.70 & 0.63 & 0.62 & 0.54 & 0.64 \\
\hline & & Recall & 0.50 & 0.58 & 0.57 & 0.57 & 0.54 & 0.55 \\
\hline & & F1 Score & 0.58 & 0.64 & 0.60 & 0.59 & 0.54 & 0.59 \\
\hline
\end{tabular}

$$
\text { F1 score }=2 \times \frac{P \times R}{P+R}
$$

In this study, we use two test scenarios; and the first is a test based on the number of rating items known to the player, and the second is based on differences in the composition of the items entered by the player. Table 2 shows the comparison of accuracy, precision, recall, and F1 scores based on the first scenario. Four experiments combine input items from different players, namely $2,3,4$, and 5 . The $\mathrm{N}$ value in the Top N Recommendation shows the ranking of tourist destination recommendations generated by MCRS. For example, if $\mathrm{N}=1$, the system produces 1 recommendation rating, and if $\mathrm{N}=5$, the system produces 5 recommendation ratings. This test does not use a minimum number of items $=1$ because the MCRS in this study uses the Cosine-based similarity method, which requires a comparison item rating value to calculate the level of similarity between users.

The test results in Table 2 show that the number of items used as player input affects the level of 


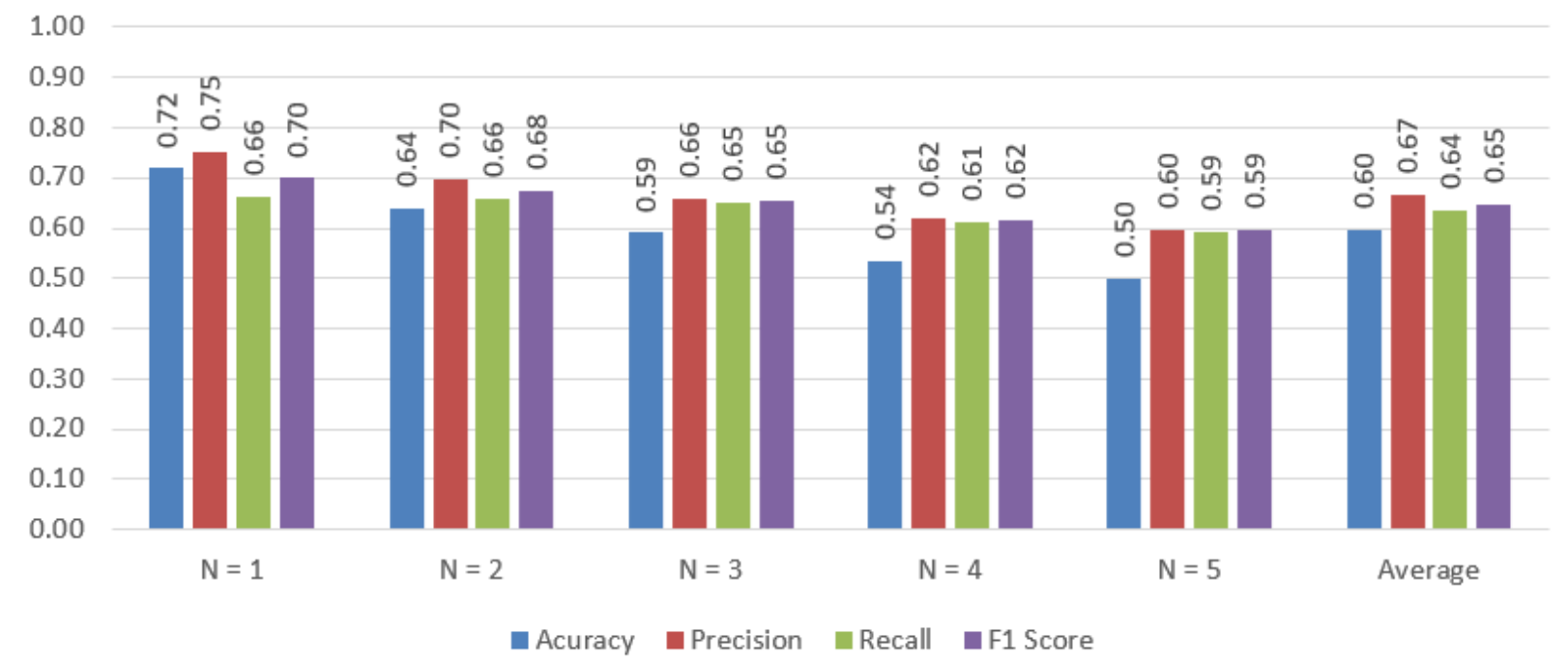

Figure. 4 Average accuracy, precision, recall and F1 scores from 40 experiments with different input item configurations

Table 4. Comparation of methods, applications, objects, and the result of accuracy, precision, recall and F1 score

\begin{tabular}{|c|c|c|c|c|c|c|c|}
\hline \multirow[b]{2}{*}{$\begin{array}{c}\text { Referenc } \\
\text { e }\end{array}$} & \multirow[b]{2}{*}{ Method } & \multirow[b]{2}{*}{ Application } & \multirow[b]{2}{*}{ Object } & \multicolumn{4}{|c|}{ Result } \\
\hline & & & & Accuracy & Precision & Recall & $\begin{array}{c}\text { F1 } \\
\text { Score }\end{array}$ \\
\hline$[34]$ & $\begin{array}{l}\text { WSM based } \\
\text { MCRS }\end{array}$ & $\begin{array}{l}\text { Web based } \\
\text { Recommendation }\end{array}$ & $\begin{array}{l}\text { General } \\
\text { tourism } \\
\text { destinations }\end{array}$ & - & - & - & - \\
\hline$[32]$ & ELECTRE & $\begin{array}{l}\text { Web based } \\
\text { Traveller's } \\
\text { Information }\end{array}$ & $\begin{array}{l}\text { General } \\
\text { traveller } \\
\text { itinerary }\end{array}$ & - & 0.67 & 0.71 & 0.68 \\
\hline$[33]$ & $\mathrm{K}$-means and GA & $\begin{array}{l}\text { Mobile } \\
\text { Recommendation } \\
\text { System }\end{array}$ & $\begin{array}{l}\text { General } \\
\text { tourism } \\
\text { destinations }\end{array}$ & - & 0.84 & 0.50 & 0.63 \\
\hline \multirow{2}{*}{ Ours } & $\begin{array}{l}\text { DR based MCRS } \\
\text { for } N=1 \\
\text { (highest result) }\end{array}$ & \multirow{2}{*}{ Tourism Game } & $\begin{array}{l}\text { Halal } \\
\text { tourism } \\
\text { destinations }\end{array}$ & 0.72 & 0.75 & 0.66 & 0.70 \\
\hline & $\begin{array}{l}\text { DR based MCRS } \\
\text { for } \mathrm{N}=1 \text { to } \mathrm{N}=5 \\
\text { (average result) }\end{array}$ & & $\begin{array}{l}\text { Halal } \\
\text { tourism } \\
\text { destinations }\end{array}$ & 0.60 & 0.67 & 0.64 & 0.65 \\
\hline
\end{tabular}

accuracy, precision, recall, and F1 score. Where the highest accuracy is 0.79 for $\mathrm{N}=1$ with number of items $=3$, while the highest precision value is 0.80 for $\mathrm{N}=1$ with number of items $=2$. Furthermore, the highest recall value is 1.00 for $\mathrm{N}=1$ with number of items $=3$, while the highest $\mathrm{F} 1$ score is 0.76 for $\mathrm{N}=$ 1 with number of items $=2$. The test results in Table 2 also show that for the recommended ranking $\mathrm{N}=1$, $\mathrm{N}=2$, and $\mathrm{N}=3$, the highest accuracy is $0.79,0.71$, 0.59 when using 3 input items. For $\mathrm{N}=4$, the highest accuracy is 0.50 when using 5 input items, and for $\mathrm{N}$ $=4$, the highest accuracy is 0.47 when using 2 or 5 input items. The highest average value for accuracy, precision, recall, and $\mathrm{F} 1$ score for $\mathrm{N}=1$ to $\mathrm{N}=5$ are $0.62,0.63,0.63$, and 0.60 .

Furthermore, Table 3 shows that differences in the composition of input rating players affect the accuracy, precision, recall, and F1 scores of the recommendations produced by MCRS. The highest accuracy, precision, recall, and F1 scores are 0.82 , $0.90,0.75$, and 0.82 on the recommendation ranking $\mathrm{N}=1$ with the item combination Jatim Park 2 and Jatim Park 3. While the combination of accuracy, precision, recall, and $\mathrm{F} 1$ scores is the best for the recommended ranking of $\mathrm{N}=2, \mathrm{~N}=4$, and $\mathrm{N}=5$ is when using a combination of BNS and Eco Green Park input items. Furthermore, specifically for the recommendation ranking $\mathrm{N}=4$, the highest accuracy, precision, recall, and F1 scores were 0.59, 0.70, 0.70, and 0.70 , namely when using a combination of input items Museum Angkut and Selecta. Of the ten test experiments shown in Table 3, BNS and Eco Green Park became the best input items with an average accuracy value $=0.68$, precision $=0.75$, recall $=0.73$ 


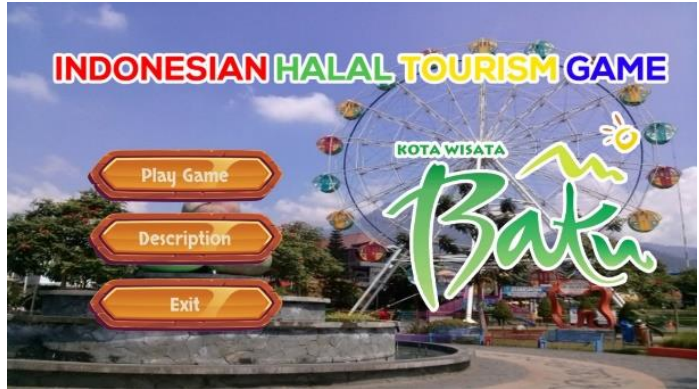

(a)

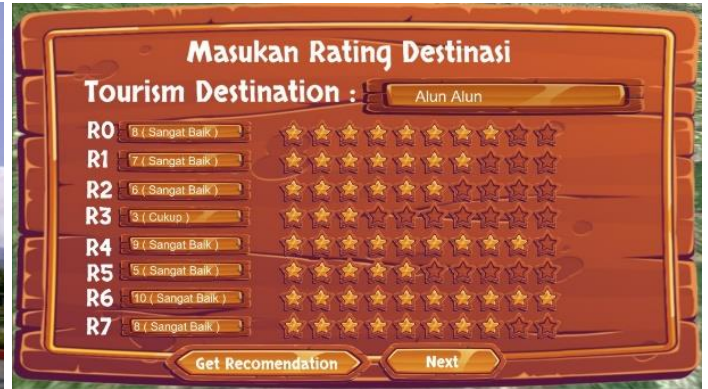

(b)

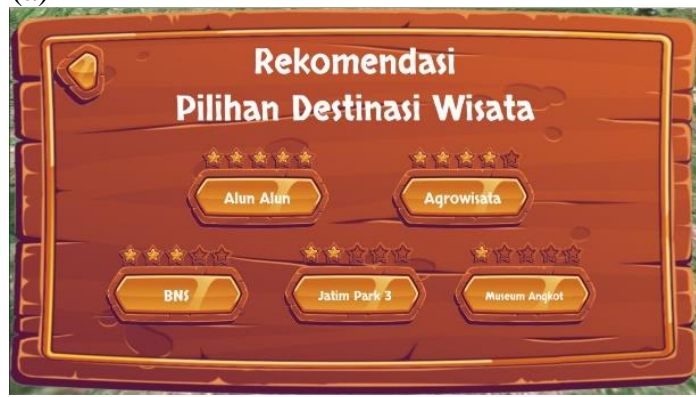

(c)

Figure. 5 Visualization of the menu display in the Indonesian Halal Tourism Game: (a) main menu, (b) halal Tourism destinations ratings input, and (c) top 5 halal tourism destinations result

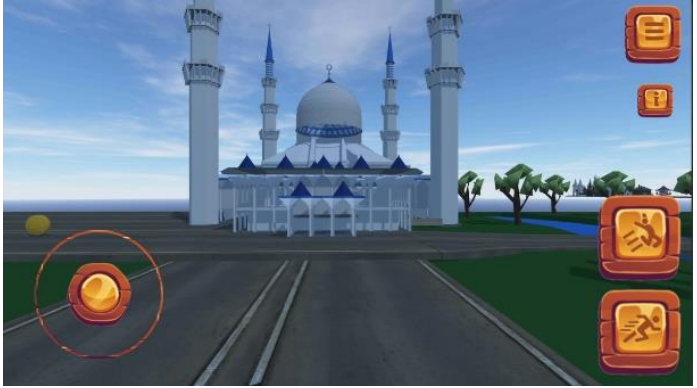

(a)

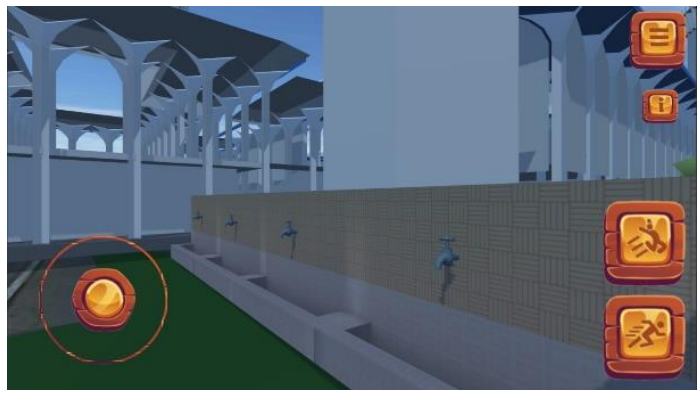

(c)

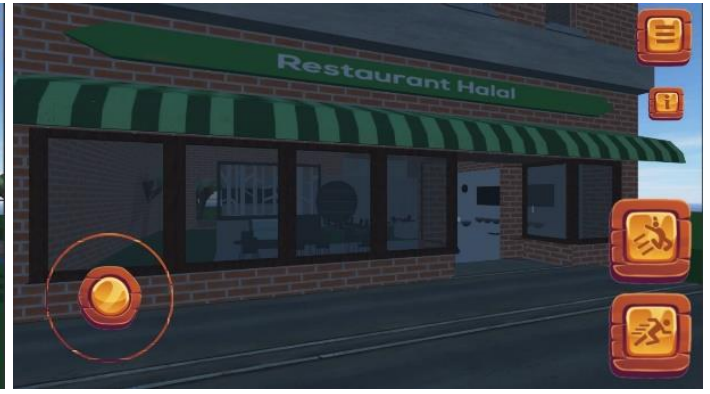

(b)

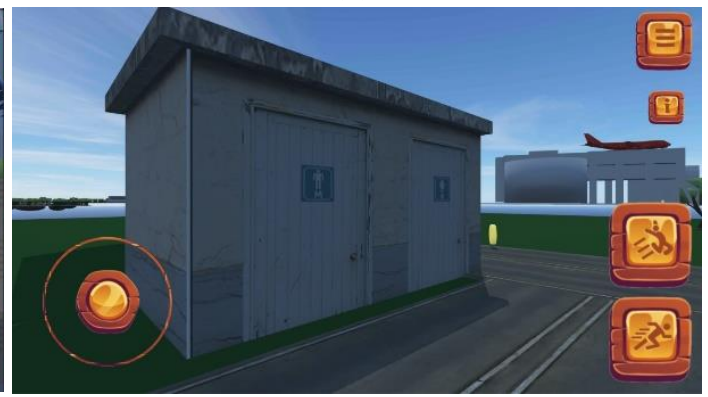

(d)

Figure. 6 Examples of virtual environment visualization in halal tourist destinations: (a) mosque, (b) halal restaurant, (c) ablution facilities, and (d) toilet facilities

and $\mathrm{F} 1$ score $=0.74$.

Fig. 4 shows the average value of accuracy, precision, recall, and $\mathrm{F} 1$ scores in 40 experiments with different input rating item configurations. The configuration has several inputs ranked from 2, 3, 4, and 5 items, with each item consisting of 10 different compositions of item types of tourism destinations. The test results show that the greater the value of $\mathrm{N}$, the smaller the value of accuracy, precision, recall, and F1 score. The highest accuracy, precision, recall, and $\mathrm{F} 1$ scores are when $\mathrm{N}=1$, namely $0.72,0.75$, 0.66 , and 0.70 . While the highest accuracy, precision, recall, and $\mathrm{F} 1$ scores are when $\mathrm{N}=5$, namely 0.50 , $0.60,0.59$, and 0.59. Furthermore, testing on 40 experiments has an average value of accuracy $=0.60$, precision $=0.67$, recall $=0.64$ and $\mathrm{F} 1$ score $=0.65$.

Next, we show a comparison of methods, applications, objects, and results in the values of 
accuracy, precision, recall, and F1 scores between our proposed system and several related papers, as shown in Table 4. From several references in the table, paper [34] uses a method almost the same as our research, namely MCRS. The difference is that they use a WSM basis implemented in a web-based recommendation application, while we use a DRbased MCRS implemented in a tourism game. However, the authors in the paper have not included the results of accuracy, precision, recall, and F1 scores, so that the results cannot be compared more deeply. Table 4 shows that the proposed DR-based MCRS system for $\mathrm{N}=1$ has an accuracy value, and an $\mathrm{F} 1$ score is higher than the others. While the value of precision and recall, DR-based MCRS for $\mathrm{N}=1$ still has not got the highest value, although the value is also not the lowest.

\subsection{Game implementation result}

In this section, we want to show the implementation and visualization of the results of the recommender system through the Indonesian halal tourism game. Fig. 5 shows the visualization of some of the main menus in the game. Fig. 5 (a) is the initial menu displayed after the player starts to enter the game. Next, Fig. 5 (b) presents a menu that assesses the criteria for halal tourist destinations known to the player as input for the recommender system. After the recommendation system processes and produces recommendations for halal tourist destinations for players, the game displays the Top 5 recommendations results as shown in Fig. 5 (c).

Next, Fig. 6 shows some examples of virtual environment visualization in travel scenarios that support halal tourism criteria. Fig. 6 (a) visualizes the player's travel journey in front of a mosque in a tourist destination, while Fig. 6 (b) visualizes a tourist trip when in front of a halal restaurant. Fig. $6 \mathrm{c}$ is an example of visualizing a virtual environment when the player is in one of the ablution facilities in a tourist destination, then Fig. 6 (c), while Fig. 6 (d) visualizes a virtual environment when players are in toilet facilities at tourist destinations.

\section{Conclusions}

This study proposes developing a recommender system to support knowledge resources for players in the Indonesian halal tourism game. We use the MCRS method based on tourism destinations rating data to recommend halal tourist destinations for players. The MCRS in this study used eight criteria $R_{0}, R_{1}, R_{2}, R_{3}, R_{4}, R_{5}, R_{6}$, and $R_{7}$ as a reference in producing recommendations. After the system produces the Top 5 recommendations, the game then displays each of these recommendations as a choice of travel scenario for the player.

In the implementation phase, we are building an Indonesian halal tourism game using the Unity game engine. The case study and theme of the game is about traveling to 14 tourist destinations in Batu City. Furthermore, the recommender system test results show that the number of inputs and the composition of the tourist destination rating inputs affects the accuracy, precision, recall, and F1 scores obtained. The test results show that the MCRS has an average value of accuracy $=0.60$, precision $=0.67$, recall $=$ 0.64 and $\mathrm{F} 1$ score $=0.65$ based on 40 experiments for $\mathrm{N}=1$ to $\mathrm{N}=5$ with different input rating configurations. While the results of the highest recommendation test scores are for $\mathrm{N}=1$, namely accuracy $=0.72$, precision $=0.75$, recall $=0.66$ and $\mathrm{F} 1$ score $=0.70$.

\section{Conflicts of interest}

The authors declare no conflict of interest.

\section{Author contributions}

Conceptualization, Y.M. Arif, and M. Hariadi; methodology, Y.M. Arif, S.M.S. Nugroho, and M. Hariadi; software, Y.M. Arif, and H. Nurhayati; validation, Y.M. Arif, H. Nurhayati, and M. Hariadi; formal analysis, Y.M. Arif, H. Nurhayati, and M. Hariadi; investigation, Y.M. Arif, S.M.S. Nugroho, and M. Hariadi; resources, Y.M. Arif, and H. Nurhayati; data curation, Y.M. Arif; writingoriginal draft preparation, Y.M. Arif, H. Nurhayati, and M. Hariadi; writing - review and editing, Y.M. Arif, S.M.S. Nugroho, and M. Hariadi; visualization, Y.M. Arif, and H. Nurhayati; supervision, S.M.S. Nugroho, and M. Hariadi; project administration, Y.M. Arif, and H. Nurhayati; funding acquisition, Y.M. Arif, and H. Nurhayati.

\section{Acknowledgments}

This paper is part of the output of the interdisciplinary research cluster in 2021 from Lembaga Penelitian dan Pengabdian Masyarakat, Universitas Islam Negeri Maulana Malik Ibrahim, Malang. Therefore, the authors would like to thank the Litabdimas program from the Direktorat Pendidikan Tinggi Keagamaan Islam, Direktorat Jenderal Pendidikan Islam, Kementrian Agama Republik Indonesia.

\section{References}

[1] A. Haryana, "Economic and Welfare Impacts of Indonesia's Tourism Sector", J. Perenc. 
Pembang. Indones. J. Dev. Plan., Vol. 4, No. 3, pp. 300-311, 2020, doi: 10.36574/jpp.v4i3.127.

[2] A. Cholik, "The Development of Tourism Industry in Indonesia: Current Problems and Challenges", Eur. J. Res. Reflect. Manag. Sci., Vol. 5, No. 1, pp. 49-59, 2017, [Online]. Available: www.idpublications.org.

[3] M. Battour and M. N. Ismail, "Halal tourism: Concepts, practises, challenges and future", Tour. Manag. Perspect., Vol. 19, pp. 150-154, 2016, doi: 10.1016/j.tmp.2015.12.008.

[4] R. Carollina and A. Triyawan, "Analysis of Halal Tourism Development Strategy in East Java Province", J. Islam. Econ. Philanthr., Vol. 2, No. 1, pp. 234-250, 2019, [Online]. Available: Pariwisata, Konsep Halal, Destinasi, Faktor Eksternal dan\%0AInternal.

[5] C. Lamsfus, D. Martin, and A. A. Sorzabal, "Smart Tourism Destinations: An Extended Conceptiomn of Smart Cities Focusing on Human Mobility", Inf. Commun. Technol. Tour. 2015, pp. 363-375, 2015, doi: 10.1007/978-3319-14343-9.

[6] N. A. Dwityas, "Social Media in Travel Decision Making Process", Int. J. Humanit. Soc. Sci., Vol. 7, No. 7, pp. 291-292, 2017.

[7] D. Gavalas and M. Kenteris, "A web-based pervasive recommendation system for mobile tourist guides", Pers. Ubiquitous Comput., Vol. 15, No. 7, pp. 759-770, 2011, doi: 10.1007/s00779-011-0389-x.

[8] Y. M. Arif, S. Harini, S. M. S. Nugroho, and M. Hariadi, "An Automatic Scenario Control In Serious Game To Visualize Tourism Destinations Recommendation", IEEE Access, Vol. 9, pp. 89941-89957, 2021, doi: 10.1109/access.2021.3091425.

[9] F. Xu, D. Buhalis, and J. Weber, "Serious games and the gami fication of tourism", Tour. Manag., Vol. 60, pp. 244-256, 2017, doi: 10.1016/j.tourman.2016.11.020.

[10] A. Coghlan and L. Carter, "Serious games as interpretive tools in complex natural tourist attractions", J. Hosp. Tour. Manag., Vol. 42, pp. 258-265, 2020, doi: 10.1016/j.jhtm.2020.01.010.

[11] Y. M. Arif, R. P. Pradana, H. Nurhayati, S. M. S. Nugroho, and M. Hariadi, "A Blockchain-Based Multiplayer Transaction For Tourism Serious Game", In: Proc. of International Conference on Computer Engineering, Network, and Intelligent Multimedia (CENIM), pp. 138-143, 2020.

[12] A. Ghirvu, "In-Game Advertising: Advantages And Limitations For Advertisers", USV Ann. Econ. Public Adm., Vol. 12, No. 115, pp. 114119, 2012.
[13] M. Faisal, H. Nurhayati, Y. M. Arif, F. Kurniawan, and F. Nugroho, "Immersive Bicycle Game For Health Virtual Of UIN Maulana Malik Ibrahim Malang", J. Teknol., Vol. 5, No. 78, pp. 325-328, 2015.

[14] W. Looi, M. Dhaliwal, R. Alhajj, and J. Rokne, "Recommender system for items in DOTa 2", IEEE Trans. Games, Vol. 11, No. 4, pp. 396-404, 2019, doi: 10.1109/TG.2018.2844121.

[15] P. Thiengburanathum, "An intelligent destination recommendation system for tourists", PQDT - UK Irel., No. March, 2018, [Online]. Available:

https://search.proquest.com/docview/20837460 43 ? accountid=49007\%0Ahttp://www.yidu.edu. $\mathrm{cn} /$ educhina/educhina.do? artifact $=\&$ svalue $=\mathrm{An}$ +intelligent+destination+recommendation+syst em+for+tourists\&stype $=2 \& \mathrm{~s}=\mathrm{on} \% 0 \mathrm{Ahttp}: / / \mathrm{sfx}$. cceu.org.cn:3410/bisu?url_ver=Z39.88-2004.

[16] Y. M. Arif, H. Nurhayati, F. Kurniawan, S. M. S. Nugroho, and M. Hariadi, "Blockchain-Based Data Sharing for Decentralized Tourism Destinations Recommendation System", Int. J. Intell. Eng. Syst., Vol. 13, No. 6, pp. 472-486, 2020, doi: 10.22266/ijies2020.1231.42.

[17] J. L. N. A. and F. J. Ma, "The influence of distance and prices on the choice of tourist destinations: The moderating role of motivations' s", Tour. Manag., Vol. 27, No. 5, pp. 982-996, 2006, doi: 10.1016/j.tourman.2005.09.009.

[18] Y. M. Arif, S. M. S. Nugroho, and M. Hariadi, "Selection of Tourism Destinations Priority using 6AsTD Framework and TOPSIS", In: Proc. of 2019 2nd International Seminar on Research of Information Technology and Intelligent Systems, ISRITI 2019, 2019, pp. 346351, doi: 10.1109/ISRITI48646.2019.9034671.

[19] G. Adomavicius and Y. Kwon, Multi-Criteria Recommender Systems, Recommende, New York: Springer Science+Business Media, 2015.

[20] D. K. Behera, M. Das, S. Swetanisha, and P. K. Sethy, "Hybrid model for movie recommendation system using content K-nearest neighbors and restricted Boltzmann machine", Indones. J. Electr. Eng. Comput. Sci., Vol. 23, No. 1, pp. 445-452, 2021, doi: 10.11591/ijeecs.v23.i1.pp445-452.

[21] X. Zheng, Y. Luo, L. Sun, J. Zhang, and F. Chen, "A tourism destination recommender system using users' sentiment and temporal dynamics", J. Intell. Inf. Syst., Vol. 51, No. 3, pp. 557-578, 2018, doi: 10.1007/s10844-018-0496-5.

[22] Y. Huang and L. Bian, "A Bayesian network and analytic hierarchy process based personalized 
recommendations for tourist attractions over the Internet", Expert Syst. Appl., Vol. 36, No. 1, pp. 933-943, 2009, doi: 10.1016/j.eswa.2007.10.019.

[23] E. D. Satriana and H. D. Faridah, "Halal Tourism: Development, Chance and Challenge", J. Halal Prod. Res., Vol. 1, No. 2, p. 32, 2018, doi: 10.20473/jhpr.Vol.1-issue.2.32-43.

[24] M. Hassan and M. Hamada, "A Neural Networks Approach for Improving the Accuracy of Multi-Criteria Recommender Systems", Appl. Sci., Vol. 7, No. 868, pp. 1-18, 2017, doi: 10.3390/app7090868.

[25] C. Corrêa and C. Kitano, "Gamification in Tourism: Analysis of Brazil Quest Game 1 Introduction and Theoretical Background", ENTER 2015 Conf. Inf. Commun. Technol. Tour., Vol. 8, No. 3, pp. 1-2, 2015, doi: 10.19080/PBSIJ.2018.08.555740.

[26] J. Swacha and R. Ittermann, "Enhancing the tourist attraction visiting process with gamification: key concepts", Eng. Manag. Prod. Serv., Vol. 9, No. 4, pp. 59-66, 2017, doi: 10.1515/emj-2017-0031.

[27] C. S. G. González, P. A. T. Delgado, V. Cruz, and P. V. T. Carrion, "Serious games for rehabilitation: Gestural interaction in personalized gamified exercises through a recommender system", J. Biomed. Inform., Vol. 97, No. December 2018, p. 103266, 2019, doi: 10.1016/j.jbi.2019.103266.

[28] J. Borràs, A. Moreno, and A. Valls, "Intelligent tourism recommender systems: A survey", Expert Syst. Appl., Vol. 41, No. 16, pp. 73707389, 2014, doi: 10.1016/j.eswa.2014.06.007.

[29] Z. Bahramian, R. A. Abbaspour, and C. Claramunt, "A Cold Start Context-Aware Recommender System for Tour Planning Using Artificial Neural Network and Case Based Reasoning", Mob. Inf. Syst., Vol. 2017, No. 18, pp. 1-18, 2017.

[30] L. Kzaz, "Tourism Recommender Systems : An Overview of Recommendation Approaches", Int. J. Comput. Appl., Vol. 180, No. 20, pp. 9-13, 2018.

[31] E. Researcher, "Factors Influencing the Motivation of Young People When Choosing a City Destination in Europe - a Case Study From Esbjerg (Denmark)", European Researcher, Vol. 69, No. 2, pp. 414-428, 2014.

[32] S. Moussa, M. Soui, and M. Abed, "User Profile and Multi-Criteria Decision Making: Personalization of Traveller's Information in Public Transportation", In: Proc. of 17th International Conference in Knowledge Based and Intelligent Information and Engineering Systems - KES2013, 2013, pp. 411-420.

[33] M. Tenemaza, S. L. Mora, A. D. Antonio, and J. Ramirez, "Improving itinerary recommendations for tourists through metaheuristic algorithms: An optimization proposal", IEEE Access, Vol. 8, No. 2, pp. 79003-79023, 2020, doi: 10.1109/ACCESS.2020.2990348.

[34] P. I. Santosa, A. Cahyono, and K. Auliasari, "A multi-criteria recommender system for tourism destination", In: Proc. of Pacific Asia Conf. Inf. Syst. PACIS 2012, 2012.

[35] M. Hassan and M. Hamada, "Enhancing learning objects recommendation using multicriteria recommender systems", In: Proc. of 2016 IEEE Int. Conf. Teaching, Assess. Learn. Eng. TALE 2016, No. December, pp. 62-64, 2017, doi: 10.1109/TALE.2016.7851771.

[36] Z. Fayyaz, M. Ebrahimian, D. Nawara, A. Ibrahim, and R. Kashef, "applied sciences Recommendation Systems: Algorithms, Challenges, Metrics, and Business Opportunities", Appl. Sci., Vol. 10, No. 7748, pp. 1-20, 2020.

[37] H. A. Id, M. A. Abdulgabber, A. Romli, and H. Kahtan, "An improved memory-based collaborative filtering method based on the TOPSIS technique", PLoS One, Vol. October, pp. 1-26, 2018. 